\title{
A comparison of physician emigration from Africa to the United States of America between 2005 and 2015
}

\author{
Robbert J. Duvivier ${ }^{1,2^{*}}$, Vanessa C. Burch ${ }^{3}$ and John R. Boulet ${ }^{1}$
}

\begin{abstract}
Background: Migration of health professionals has been a cause for global concern, in particular migration from African countries with a high disease burden and already fragile health systems. An estimated one fifth of Africanborn physicians are working in high-income countries. Lack of good data makes it difficult to determine what constitutes "African" physicians, as most studies do not distinguish between their country of citizenship and country of training. Thus, the real extent of migration from African countries to the United States (US) remains unclear. This paper quantifies where African migrant physicians come from, where they were educated, and how these trends have changed over time.

Methods: We combined data from the Educational Commission for Foreign Medical Graduates with the 2005 and 2015 American Medical Association Physician Masterfiles. Using a repeated cross-sectional study design, we reviewed the available data, including medical school attended, country of medical school, and citizenship when entering medical school.

Results: The outflow of African-educated physicians to the US has increased over the past 10 years, from 10684 in 2005 to 13584 in 2015 (27.1\% increase). This represents 5.9\% of all international medical graduates in the US workforce in 2015. The number of African-educated physicians who graduated from medical schools in sub-Saharan countries was 2014 in 2005 and 8150 in 2015 (304.6\% increase). We found four distinct categorizations of African-trained physicians migrating to the US: (1) citizens from an African country who attended medical school in their own country (86.2\%, $n=11,697)$; (2) citizens from an African country who attended medical school in another African country $(2.3 \%, n=317)$; (3) US citizens who attended medical school in an African country (4.0\%, $n=537)$; (4) citizens from a country outside Africa, and other than the United States, who attended medical school in an African country $(7.5 \%, n=1013)$. Overall, six schools in Africa provided half of all African-educated physicians.
\end{abstract}

Conclusions: The number of African-educated physicians in the US has increased over the past 10 years. We have distinguished four migration patterns, based on citizenship and country of medical school. The majority of African graduates come to the US from relatively few countries, and from a limited number of medical schools. A proportion are not citizens of the country where they attended medical school, highlighting the internationalization of medical education.

Keywords: International medical graduates, Medical education, Medical schools, Africa, Migration, Brain drain

\footnotetext{
* Correspondence: robbertduvivier@gmail.com

${ }^{1}$ Foundation for Advancement of International Medical Education and

Research (FAIMER), Philadelphia, United States of America

${ }^{2}$ Medical Education Unit, School of Medicine and Public Health, University of

Newcastle, University Drive, Callaghan, NSW 2308, Australia

Full list of author information is available at the end of the article
} 


\section{Background}

The large-scale emigration of highly skilled and welleducated workers has been likened to a "brain drain" [1]. Migration of health professionals in particular has been a cause for global concern [2], in particular migration from African countries with a high disease burden and already fragile health systems. Among others, the World Health Organization [3] and the US Institute of Medicine [4] have noted the negative consequences of midwives, nurses, and physicians leaving Africa. An estimated one fifth of African-born physicians are working in high-income countries ${ }^{1}$. The top four recipient countries employing doctors trained elsewhere are Australia, Canada, the United Kingdom (UK), and the United States (US) [5]. These four countries derive around one quarter of their workforce from international medical graduates (IMGs), the majority emigrating from lower-income countries [6]. Of these four recipient nations, the US employs three quarters of all IMGs worldwide. The US has relied on IMGs to supplement its physician workforce since the 1950s [6], with the number of internationally trained doctors tripling from 70646 in 1973 [7] to 210000 in 2003 [8]. The estimated number of African IMGs in the US in 2004 was 5334 (2002 data [8], from a subset of sub-Saharan countries); in 2013, there were 17376 physicians either born or trained in Africa in the US physician workforce (2011 data [9]).

In light of these figures, public and academic attention has centered on the ethics of employing doctors who have been trained in lower-income countries [10, 11]. However, despite the plethora of literature on health worker migration, there is a remarkable paucity and incompleteness of data [12, 13]. Moreover, most of the literature on African IMGs has tended to focus on a particular sub-region, namely sub-Saharan Africa $[7,8,14,15]$. Such previous studies that address migration have treated all graduates from an African medical school as African IMGs, with no distinction between an individual's country of citizenship and country of training. This makes it difficult to determine the real scope of migration from African countries to the US, or other nations, and thus develop meaningful national or international workforce policies [16, 17].

The purpose of this paper is to provide a profile of African-trained physicians working in the US, reviewing both historical patterns and recent emigration trends. Our methodology differs from previous studies $[8,9]$ in that we combined data sources to obtain information at both the school level and the individual level. We specifically investigated the citizenship status of Africantrained physicians who sought educational and practice opportunities in the US.

\section{Methods}

We obtained information about all African-trained physicians working in the US from the 2005 and 2015 American Medical Association (AMA) Physician Masterfiles [18]. The AMA Masterfile contains information on physicians practicing in the US, including type of practice and major professional activity. We used data from physicians who were active, including those who are employed in non-clinical positions such as research, teaching, or administration. To be listed in the AMA Masterfile, an IMG must have started a residency program in the US. Using a unique identifier, we combined individual AMA records with demographic information available from the Educational Commission for Foreign Medical Graduates (ECFMG). The ECFMG certifies all IMGs who wish to obtain residency positions in the US; for IMGs, ECFMG certification and residency training is required to obtain an unrestricted license to practice medicine. As part of the certification process, ECFMG collects demographic information, including citizenship at entry to medical school. For the purpose of this paper, we defined international medical graduates (IMGs) as individuals who attended medical schools located outside the US or Canada. Physicians who were educated in Africa, regardless of citizenship at entry to medical school, are referred to as African-educated IMGs. Those who were educated in a medical school in sub-Saharan Africa (SSA), regardless of citizenship, were designated as SSA IMGs. The designation SSA is used to indicate all of Africa except northern Africa, with the Sudan included in sub-Saharan Africa, as specified in the statistics of UN institutions. ${ }^{1}$ Using a cross-sectional approach, we reviewed the available data, including medical school attended, country of medical school, and citizenship at entry to medical school. Data analysis was done with SAS v9 [19].

\section{Results}

Between 2005 and 2015, the active physician pool in the US increased from 836190 to 954772 , or $14.2 \%$. Figure 1 shows that of all the physicians active in the US in 2015, including those in residency programs, administration, and research and teaching positions, 228 123 , or $24 \%$, are IMGs. Altogether, 13584 of these IMGs $(5.9 \%$ of all IMGs in the US) had been educated at an African medical school. In the same time period, the number of African-educated IMGs grew from 10 684 to 13584 , a $27.1 \%$ increase. This represents a net increase of 2900 African-educated physicians since 2005, or about one African-educated doctor migrating to the US per day over the last decade.

In 2015, half (50.2\%) of all IMGs in the US workforce were educated in seven countries; India, Philippines, 


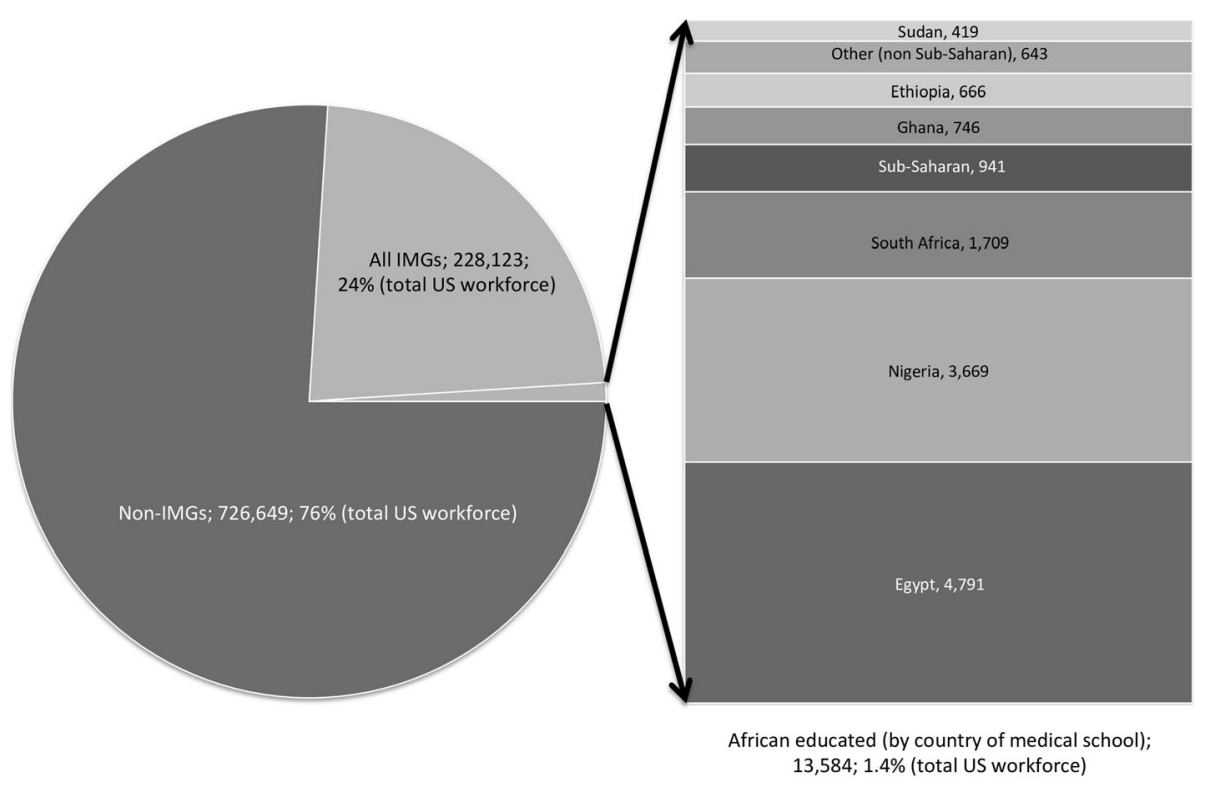

Fig. 1 IMGs in the US, 2015 data

Mexico, Pakistan, Dominican Republic, Grenada, Egypt. India alone accounted for $22.1 \%$ of all IMGs in the US in 2015. Egypt, a Northern African (non-SSA) country, is the only African nation in the top 10 source countries, and accounted for 4223 IMGs in 2005 (2.3\% of US workforce) and 4791 in 2015 (2.1\% of workforce).

Table 1 shows the country of medical school for all African-educated physicians active in the US workforce in 2005 and 2015. Four countries (Egypt, Nigeria, South Africa, and Ghana) account for the majority of African emigration: in 2015, $86.0 \%$ of all African-educated IMGs in the US attended medical school at institutions in these nations. In 2015, the total number of IMGs who were educated in medical schools in SSA countries was 8150; this was 2014 more doctors than in 2005. In 2015, those IMGs who graduated from SSA medical schools represented $60.0 \%$ of the total African-educated contingent, with Nigeria, South Africa and Ghana accounting for three quarters $(n=6124)$. Of the increase in African-educated physicians practicing in the US since 2005, 1156 were educated in Nigeria, South Africa, and Ghana-leaving a net increase of 858 SSAeducated physicians from countries other than these three in the US between 2005 and 2015.

Table 2 provides data on the citizenship (at entry to medical school) for African-educated physicians in the US workforce.

The total number of African-educated IMGs with citizenship from a country outside Africa increased by 29.3\%. Compared to 2005, in 2015 there were notably more African-educated physicians in the US with citizenship from Libya $(+256.4 \%)$, Cameroon $(+101.9 \%)$,
Sudan (+88.1\%), Ethiopia (+87.6\%), and the US (+71.6\%). In 2015, African-educated physicians (those who attended medical school in an African country) included citizens from 64 different non-African countries, including Middle-Eastern countries such as Jordan $(n=201$, none of whom attended SSA schools) and Syria $(n=72$, 3 were educated in SSA schools), Asian countries such as India $(n=184,175$ attended SSA schools) and Pakistan ( $n=71,44$ attended SSA schools), the United Kingdom ( $n=208,199$ attended SSA schools), and the US ( $n=537,362$ attended SSA schools). In total, based on 2015 data, 1552 (11.5\%) African-educated physicians held citizenship from a non-African country at entry to medical school. This leaves 11997 African-educated IMGs who held citizenship from an African country at the time of their education; 7270 (53.7\%) of whom had citizenship (at entry to medical school) of a SSA country.

For those IMGs with citizenship from an African country at entry to medical school, citizens from five countries (Egypt, Nigeria, South Africa, Ethiopia, and Ghana) account for $76.0 \%$ of all African-educated physicians in the United States (2015 data), with Egyptian (30.9\%) and Nigerian (23.9\%) physicians counting for half of this cohort. Of the sub-Saharan contingent, $89.7 \%$ were citizens of five countries: Nigeria (44.5\%), South Africa (20.4\%), Ghana (10.0\%), Ethiopia (9.2\%), and Sudan (5.6\%). Excluding these five countries, only 747 African-educated IMGs were citizens of countries in the rest of sub-Saharan Africa.

Between 2005 and 2015, there was an over 70\% increase in the number of US citizens attending African medical schools and subsequently entering the US 
Table 1 African-educated IMGs in the US physician workforce by country of medical school

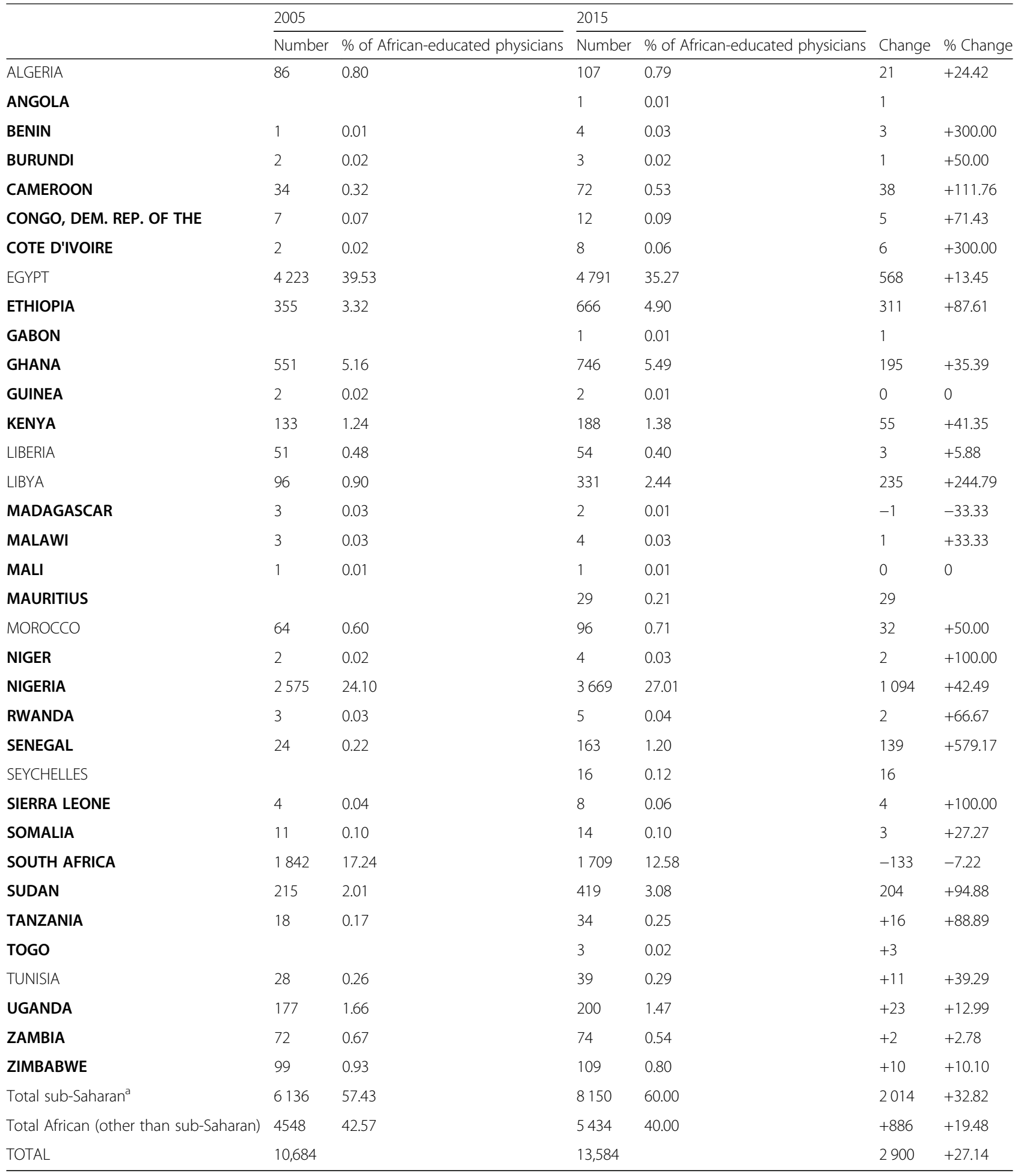

${ }^{\mathrm{a}}$ Nations in bold are considered sub-Saharan Africa

workforce. In 2015, nearly 4\% $(n=537)$ of all Africaneducated physicians in practice in the United States were US citizens at entry to medical school.
Table 3 shows, for 2005, the medical schools in Africa with greater than 100 graduates currently practicing medicine in the United States, while Table 4 shows this 
Table 2 African-educated IMGs in the US physician workforce by country of citizenship at entry to medical school

\begin{tabular}{|c|c|c|c|c|c|}
\hline & 2005 & & 2015 & & \\
\hline & Number & $\%$ of total & Number & $\%$ of total & $\%$ change \\
\hline EGYPT & 3655 & 34.27 & Err:511 & Err:511 & Err:511 \\
\hline NIGERIA ${ }^{a}$ & 2203 & 20.66 & Err:511 & Err:511 & Err:511 \\
\hline SOUTH AFRICA & 1633 & 15.31 & Err:511 & Err:511 & Err:511 \\
\hline GHANA & 547 & 5.13 & Err:511 & Err:511 & Err:511 \\
\hline ETHIOPIA & 355 & 3.33 & Err:511 & Err:511 & Err:511 \\
\hline UNITED STATES OF AMERICA & 313 & 2.94 & Err:511 & Err:511 & Err:511 \\
\hline JORDAN & 220 & 2.06 & Err:511 & Err:511 & Err:511 \\
\hline SUDAN & 218 & 2.04 & Err:511 & Err:511 & Err:511 \\
\hline UNITED KINGDOM & 180 & 1.69 & Err:511 & Err:511 & Err:511 \\
\hline KENYA & 151 & 1.42 & Err:511 & Err:511 & Err:511 \\
\hline INDIA & 140 & 1.31 & Err:511 & Err:511 & Err:511 \\
\hline ZIMBABWE & 113 & 1.06 & Err:511 & Err:511 & Err:511 \\
\hline UGANDA & 90 & 0.84 & Err:511 & Err:511 & Err:511 \\
\hline LIBYA & 78 & 0.73 & Err:511 & Err:511 & Err:511 \\
\hline ALGERIA & 77 & 0.72 & Err:511 & Err:511 & Err:511 \\
\hline PAKISTAN & 60 & 0.56 & Err:511 & Err:511 & Err:511 \\
\hline MOROCCO & 59 & 0.55 & Err:511 & Err:511 & Err:511 \\
\hline CAMEROON & 52 & 0.49 & Err:511 & Err:511 & Err:511 \\
\hline SYRIA & 52 & 0.49 & Err:511 & Err:511 & Err:511 \\
\hline LEBANON & 48 & 0.45 & Err:511 & Err:511 & Err:511 \\
\hline Other sub-Saharan & 173 & 1.62 & 200 & 1.48 & +15.61 \\
\hline Other African (non sub-Saharan) & 59 & 0.55 & 64 & 0.47 & +8.47 \\
\hline Other (non-African) & 188 & 1.76 & 234 & 1.73 & +24.47 \\
\hline Total sub-Saharan ${ }^{\mathrm{a}}$ & 5535 & 51.90 & Err:511 & Err:511 & Err:511 \\
\hline Total African (non sub-Saharan) & 3928 & 36.83 & Err:511 & 34.88 & Err:511 \\
\hline Total other (non-African) & 1201 & 11.26 & Err:511 & Err:511 & Err:511 \\
\hline
\end{tabular}

Total numbers for Table 2 differ from Table 1 because of missing citizenship information. $<0.05 \%$ of the physicians did not have citizenship information coded in the ECFMG database

${ }^{\mathrm{a}}$ Nations in bold are considered sub-Saharan Africa

for 2015. In 2015, for half of the African-educated IMGs in the US physician workforce, their Alma Mater is one of only six schools (three in Egypt, two in Nigeria, and one in South Africa), out of a total number of 208 medical schools in Africa [20]. Based on African-educated physicians in the US in 2015, $12.5 \%(n=1867)$ were non-domestic students (i.e., from a country other than that of the host university). Of these, 1550 (83.0\%) were not citizens of an African country at entry to medical school; 1013 were US citizens.

This analysis led us to consider four distinct categorizations of African-trained physicians migrating to the US: (1) citizens from an African country who attended medical school in their own country; (2) citizens from an African country who attended medical school in another African country; (3) US citizens who attended medical school in an African country; (4) citizens from a country outside Africa, and other than the United States, who attended medical school in an African country. Based on 2015 data, most of African-education IMGs were in category $1(86.2 \%, n=11697)$, followed by category 4 $(7.5 \%, n=1013)$, category $3(4.0 \%, n=537)$, and category 2 $(2.3 \%, n=317)$. This distribution was similar for 2005 data, although actual numbers varied. There are some differences between 2005 and 2015, most notably an increased number of schools with more than 100 graduates currently practicing in the US. This is a reflection of wider migration patterns for IMGs to the US. Also, some schools who appear in the 2015 list were not in operation in 2005.

\section{Discussion}

The purpose of this study was to look, at two time points, at the demographics of African-trained physicians who migrated to the US. 


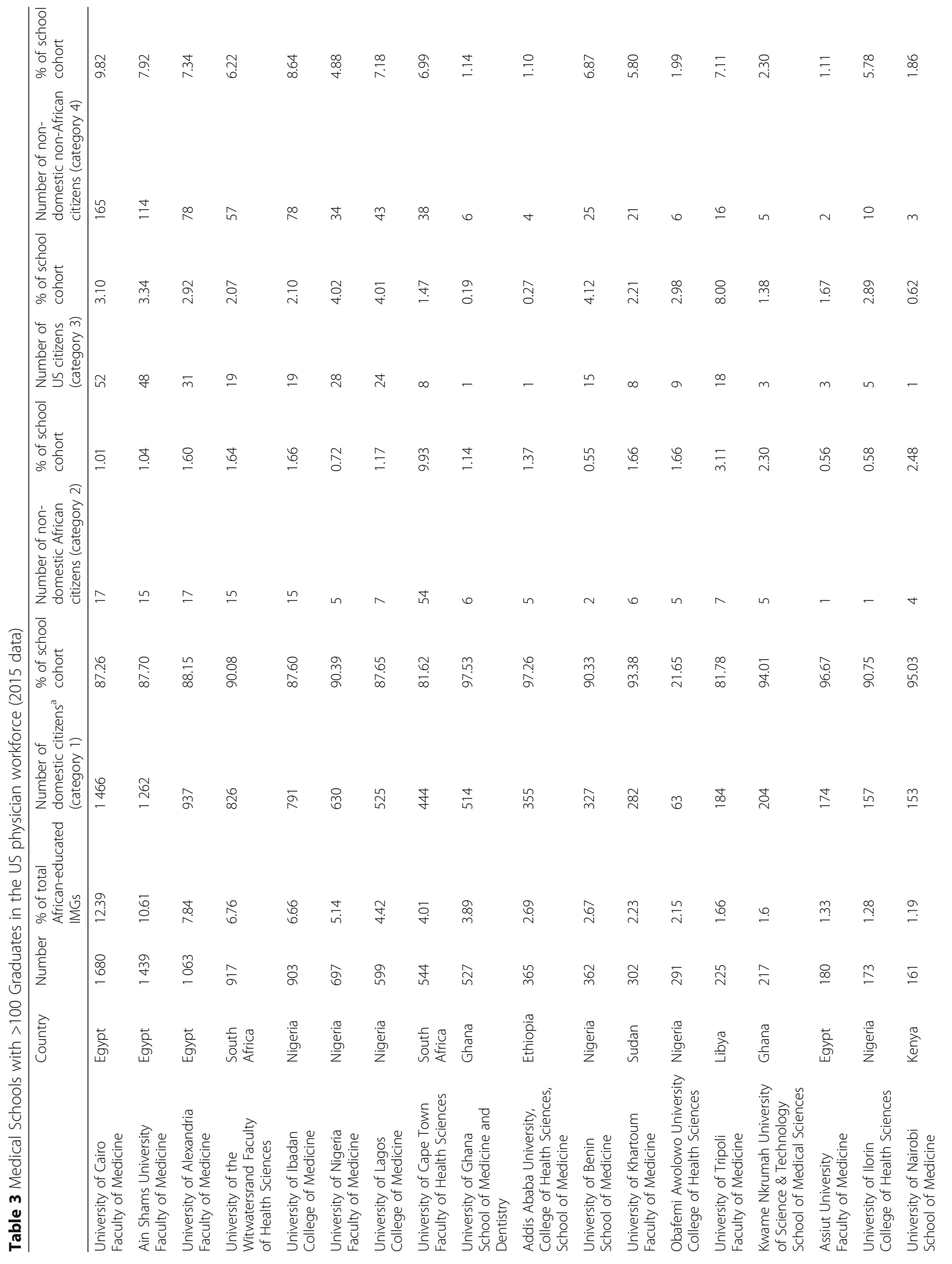




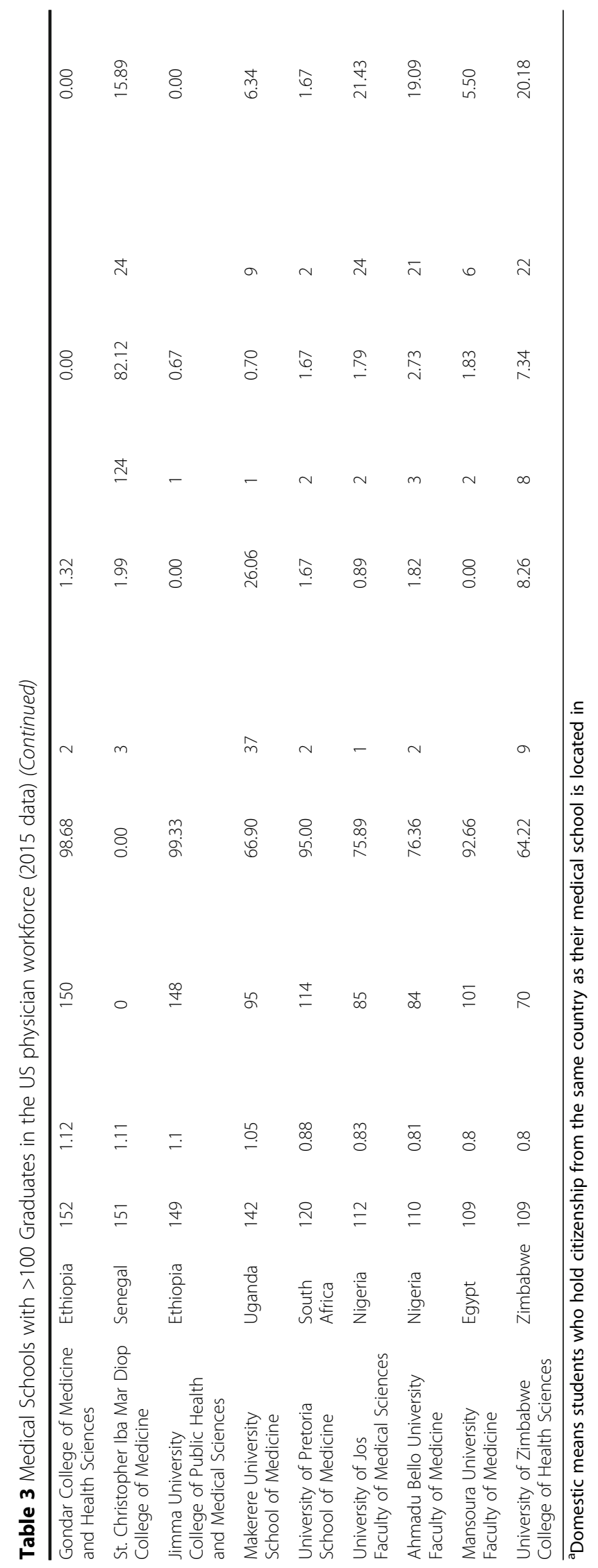




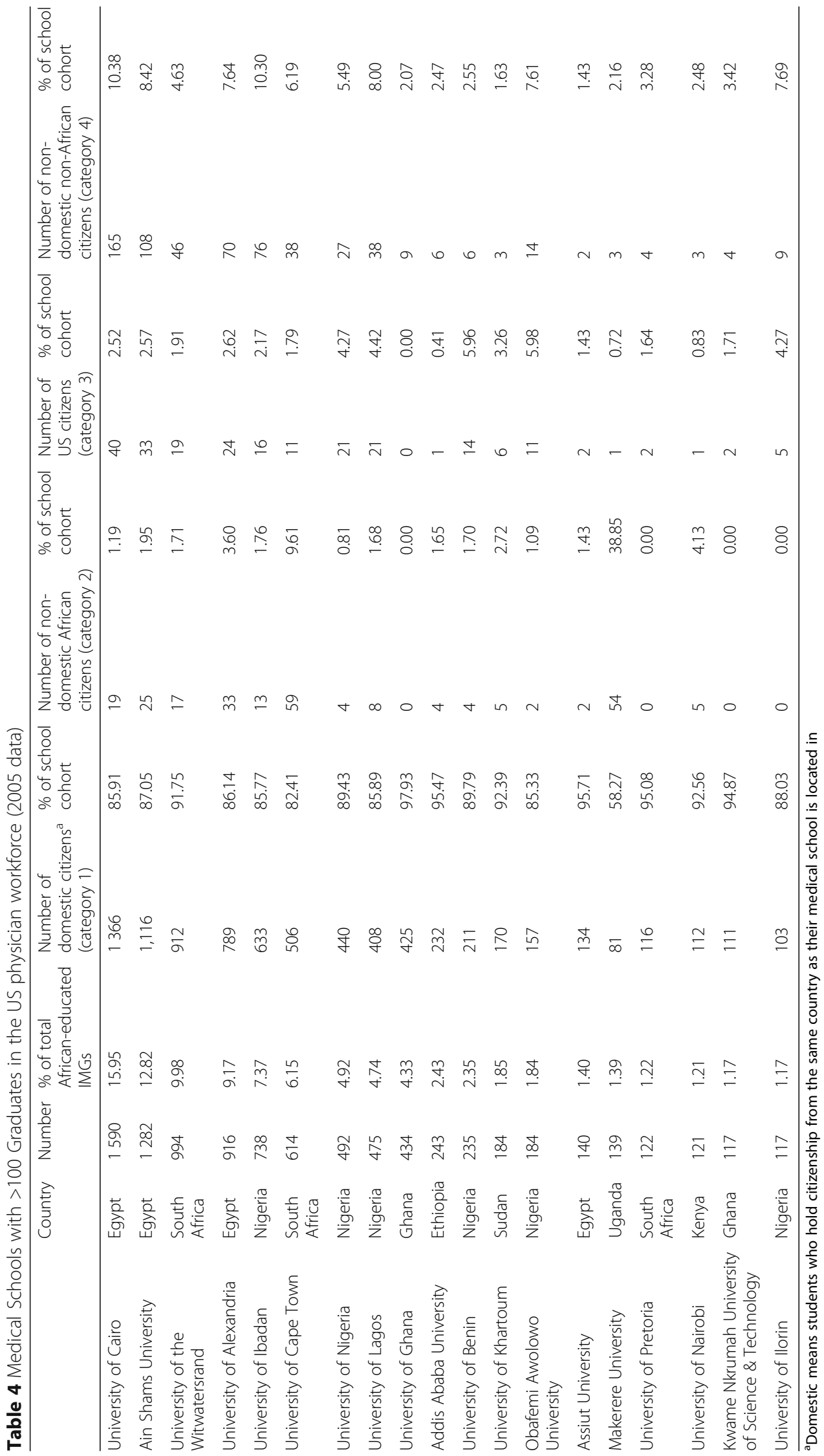


We distinguish four different patterns of migration based on citizenship and medical school attended. ${ }^{2}$ As noted by other authors [5, 9], African-educated IMGs make up a relatively small proportion of the US workforce. The number of African-educated IMGs in the US has increased substantially in the past 10 years, as has the total number of practicing physicians. A proportion of these individuals were not citizens from African countries when they first enrolled in medical school. Moreover, the majority of African-educated IMGs attended medical school in a limited number of countries and, based on 2015 data, one third of them graduated from one of three (Northern African) medical schools. While these findings highlight some trends, more studies are needed to understand the "internationalization" of African medical schools and the potential role of geopolitical and economic events in shaping physician migration.

Our investigation provides unique information to characterize the so-called brain drain and the role of particular countries and institutions in supplying physicians for non-domestic markets. Effectively ignored in previous investigations, a substantial proportion of African-educated IMGs are citizens of countries other than where they trained, with many being citizens from non-African countries. While this does not diminish the potential healthcare impact of physician migration, it helps to explain the changing dynamics of medical education on the African continent. Similar to other places in the world, students may choose their educational programs not based on the local need for practitioners, but based on admission policies and personal economic considerations [21]. To the extent that medical education is publicly funded, the migration of these individuals represents both a financial and workforce loss for these countries.

The potentially negative impact of this educational model on both the local workforce and the provision of medical care in the country of education raises some important ethical questions. When medical schools in lowincome countries educate students from other countries, only to have them leave the country after graduation, they may, in effect, be limiting their ability to address local physician supply issues. Even though foreign medical students may pay more for their education, effectively subsidizing local educational efforts, the capacity to educate a sufficient number of doctors, which is dependent on the number of matriculating students, is a limiting factor in developing an adequate local workforce. In Africa, where the number of medical schools is limited and the size of graduating classes may also be small (e.g., Uganda, Malawi) [20], the education of foreign nationals, while potentially economically advantageous, and not necessarily contributing to "brain drain", can constrain the local workforce and have negative repercussions for the local healthcare systems. As noted by the WHO, there is no health without an adequate local workforce [22].

Our study enumerates the migration patterns of African-educated physicians to the US; it is important to look at this in relation to factors that shape migration in general, and "brain drain" of health professionals in particular. These are typically framed as a combination of push and pull factors [23, 24], and include macroeconomic dynamics such as market segmentation and labour market configurations, political environment such as good governance and security from armed conflict, personal economic calculations such as wages, and professional considerations such as advanced training options and working conditions. Simply put, the literature suggests that migration is spurred by the prospects of advanced training, more attractive salaries and working conditions, and a higher standard of living [25-27]. In light of this, it is not surprising that there has been an increase in the number of Africaneducated physicians migrating to the US. The quality of graduate medical training in the US is perceived to be among the best in world and conflicts in some nations (e.g., South Sudan, Libya) would certainly incentivize some graduates to leave.

Between 2005 and 2015, there has been an increase in the number of African-educated physicians coming to the US for graduate medical education and practice opportunities. However, depending on a number of supply and demand issues, future opportunities may be limited. In the US, the Association of American Medical Colleges (AAMC) has estimated that there will be a shortage of 91500 doctors by 2020 and 130600 by 2025 [28]. To overcome this deficit, new US medical schools have opened and are under development [29]. However, with no substantial increase in the number of graduate training positions, which seems likely given the required funding [30], the number of graduates from US medical schools may eventually surpass the number of residency positions. Because US medical graduates tend to remain in their home country for specialty training, the number of IMGs who train in the US is expected to decrease [31-34]. While the impact of these policy changes on the migration of African-educated IMGs to the US remains to be seen, the principal "pull factor" of advanced training opportunities may not be as relevant in the future.

Unlike previous investigations, we were able to determine the citizenship of US physician immigrants who attended medical school in an African country. Not only did a few medical schools account for a substantial number of migrants, but many of the graduates from these schools held citizenship from another country, most 
from countries outside of Africa. While these IMGs are African-educated, it is uncertain whether they enrolled in medical school with the intention to practice locally. A similar situation exists in Central America and the Caribbean where medical schools take a disproportionate number of non-domestic applicants considering the local labor market $[35,36]$. For some schools, such as the St Christopher Iba Mar Diop College of Medicine, where $98 \%$ of graduates who currently practice in the US were non-domestic non-African citizens, it seems highly unlikely that the educational system is being driven by local healthcare needs. Even for countries that do supply a considerable number of graduates to the US physician workforce, such as Egypt, the large number of medical schools located there, and sizeable enrolment [37], may be indicative of the development of business models that encourage the export of physicians, as has been done in other regions of the world [38]. Our data show that $40.0 \%$ of African-educated physicians working in the US graduated from North African medical schools and that in total $11.4 \%$ of African-trained IMGs held citizenship of countries outside Africa. These graduates are not really contributing to the "brain drain" that impacts healthcare in SSA, except for the fact that they are taking medical school positions that could be better utilized for strengthening the local workforce. Clarifying the role of these African-trained physicians, in consideration to the "brain drain" debate, is essential if local, national, and international policies are to be put in place to address the global maldistribution of physicians and other healthcare workers.

There are a number of limitations of our investigation. First, while we looked specifically at African emigration to the US, it is important, from a total "brain drain" perspective, to note that African graduates also migrate elsewhere $[39,40]$. The full extent of African physician emigration requires data from all receiving nations. Second, there are known issues with the AMA-Master file including under/overcounting physicians in different practice settings or specialties [41]. Despite this, the AMA has been the best available source for US physician workforce data $[9,42-44]$. Third, for the comparisons, we looked separately at the 2005 and 2015 cohorts. While it is difficult, yet possible, to link individual physicians at the two time points, enabling the identification of new émigrés and, potentially, those who left practice, we were not interested in following individual practitioners over time. This longitudinal tracking of immigrant physicians would be helpful in terms of quantifying reverse migration, especially among those physicians who come to the US solely for Graduate Medical Education; however, the AMA Masterfile we used does not contain such data. Based on previous investigations, however, this reverse migration, at least from the US back to the country of origin (country of medical school education), is likely to be quite low [33, 45]. Further research could address African-educated physicians' tenure in the US medical system.

Additional limitations include lack of information on the quality of the medical schools, including curricula and competencies addressed, and the lack of comparative USMLE performance data for the African-educated physicians in our study. We were not able to establish whether the standards of education in the dominant source countries changed between 2005 and 2015, which might provide additional insight into reasons for migration. We did not determine the USMLE performance by medical school as the number of African-educated physicians taking USMLE is small for some schools and we have no method to establish the denominators, e.g., how the students leaving for the US compare to the rest of their cohort.

Putting aside the ethics of international migration of physicians [46-50], it is important to know who is leaving, where they are coming from, and where they are going. This information can be used by governments of African nations and supranational organizations such as the World Health Organization to better support African health workforce capacity efforts. While we were able to quantify the emigration of African-educated physicians to the US, future research should focus on why certain countries, and schools within these countries, are the primary source for these physicians. On a school level, research should concentrate on medical education funding models, including incentives to enroll non-domestic students and retention schemes for domestic students. While some individuals who emigrate may eventually return to their home country, and others may make reciprocal financial contributions in the future, the exodus of well-trained medical graduates is certain to challenge the educational and healthcare systems in some countries, especially those with disproportionally large burdens of disease [51]. While efforts aimed at strengthening the health systems can be productive, promoting health workforce retention will be difficult if many of those enrolled in the educational programs never had the intention of practicing locally.

\section{Conclusions}

The actual outflow of African-educated physicians to the US has increased over the past 10 years but their contribution to "brain drain" appears uneven across regions or countries.

The majority of African graduates migrating to the US come from relatively few countries, and from a limited number of medical schools. A substantial proportion were not citizens of African countries when they attended medical school. These findings highlight the 
need for more specific studies or local and national labour dynamics, including the economics of medical education. When combined with analyses from other countries (e.g., Australia, Canada, United Kingdom), they can help inform national and international workforce policies.

\section{Endnotes}

${ }^{1}$ Countries not included in sub-Saharan Africa but on the African continent are Algeria, Egypt, Libya, Morocco, Tunisia, and Western Sahara.

${ }^{2} \mathrm{~A}$ fifth pattern exists, but is not verifiable with our data. Citizens from an African country who attended medical school in a country that is not their own, and is not on the African continent, and currently practice in the US.

\section{Acknowledgements}

RD wishes to thank John Norcini for continuing mentorship and providing support for this study.

\section{Funding}

No external funding was received for this study.

\section{Availability of data and materials}

The data that support the findings of this study are available from Educational Council for Foreign Medical Graduates (ECFMG) and the American Medical Association (AMA) but restrictions apply to the availability of these data, which were used under license for the current study, and so are not publicly available. Data are however available from the authors upon reasonable request and with permission of ECFMG and AMA.

\section{Authors' contributions}

$\mathrm{RD}$ and JB designed the study, based on a previous draft paper by VB and $J B$, using a different data set. JB collected the data and $\mathrm{RD}$ and JB analyzed and interpreted the data. RD drafted the paper, with substantial input from $J B$ and VB. All authors approved the final version of the manuscript.

\section{Competing interests}

The authors declare that they have no competing interests.

\section{Consent for publication}

Not applicable.

\section{Ethics approval and consent to participate}

No ethics approval was required given the nature of the data.

\section{Publisher's Note}

Springer Nature remains neutral with regard to jurisdictional claims in published maps and institutional affiliations.

\footnotetext{
Author details

${ }^{1}$ Foundation for Advancement of International Medical Education and Research (FAIMER), Philadelphia, United States of America. ${ }^{2}$ Medical Education Unit, School of Medicine and Public Health, University of Newcastle, University Drive, Callaghan, NSW 2308, Australia. ${ }^{3}$ Department of Medicine, Faculty of Health Sciences, University of Cape Town, Cape Town, South Africa.
}

Received: 28 November 2016 Accepted: 15 June 2017

Published online: 26 June 2017

\section{References}

1. Attafi A. The brain drain: theoretical framework and hypotheses. Rev Can Etudes Dev Can J Dev Stud. 1993;15:89-99.
2. Mensah K, Mackintosh M, Henry L. The 'skills drain' of health professionals from the developing world: a framework for policy formulation. 2005.

3. WHO | The World Health Report 2006 - working together for health. WHO Available at: http://www.who.int/whr/2006/en/. (Accessed: 16 Jan 2013).

4. Lohr KN, Vanselow NA, Detmer DE, et al. The Nation's Physician Workforce:: Options for Balancing Supply and Requirements. Washington: National Academies Press; 1996.

5. Mullan F. The metrics of the physician brain drain. N Engl J Med. 2005; 353:1810-8.

6. Cooper RA. Physician migration: a challenge for America, a challenge for the world. J Contin Educ Health Prof. 2005;25:8-14.

7. Mejia A. Migration of physicians and nurses: a world wide picture. Int J Epidemiol. 1978;7:207-15.

8. Hagopian A, Thompson MJ, Fordyce M, Johnson KE, Hart LG. The migration of physicians from sub-Saharan Africa to the United States of America: measures of the African brain drain. Hum Resour Health. 2004;2:17.

9. Tankwanchi ABS, Özden C, Vermund SH. Physician emigration from subSaharan Africa to the United States: analysis of the 2011 AMA physician masterfile. PLoS Med. 2013;10:e1001513.

10. Hagopian A. Recruiting primary care physicians from abroad: is poaching from low-income countries morally defensible? Ann Fam Med. 2007;5:483-5.

11. Snyder J. Is health worker migration a case of poaching? Am J Bioeth. 2009:9:3-7.

12. Diallo K, Zurn P, Gupta N, Dal Poz M. Monitoring and evaluation of human resources for health: an international perspective. Hum Resour Health. 2003;1:3.

13. Bach S. Migration patterns of physicians and nurses: still the same story? Bull World Health Organ. 2004;82:624-5.

14. Clemens MA, Pettersson G. New data on African health professionals abroad. Hum Resour Health. 2008;6:1-11.

15. Lututala BM. The brain drain in Africa: state of the issue and possible solutions. 2012.

16. Stilwell B, et al. Migration of health-care workers from developing countries: strategic approaches to its management. Bull World Health Organ. 2004;82: 595-600.

17. Stilwell $B$, et al. Developing evidence-based ethical policies on the migration of health workers: conceptual and practical challenges. Hum Resour Health. 2003; $1: 8$.

18. AMA Physician Masterfile. Available at: http://www.ama-assn.org/ama/pub/ about-ama/physician-data-resources/physician-masterfile.page. (Accessed: 4 Aug 2015)

19. Statistical Analysis Software, SAS/STAT | SAS. Available at: http://www.sas. com/en_us/software/analytics/stat.html. (Accessed: 12 Jan 2016)

20. Duvivier RJ, Boulet JR, Opalek A, Zanten M, Norcini J. Overview of the world's medical schools: an update. Med Educ. 2014;48:860-9.

21. Eckhert NL, van Zanten M. US-citizen international medical graduates-a boon for the workforce? N Engl J Med. 2015;372:1686-7.

22. Global Health Workforce Alliance, W. H. O. A universal truth: no health without a workforce. Geneva: World Health Organization; 2013.

23. Vizi ES. Reversing the brain drain from Eastern European countries: The 'push' and 'pull' factors. Technol Soc. 1993;15:101-9.

24. Schoorl J, Heering L, Esveldt I, Groenewold G, van der Erf R. Push and pull factors of international migration: a comparative report. 2000.

25. Astor $A$, et al. Physician migration: views from professionals in Colombia, Nigeria, India, Pakistan and the Philippines. Soc Sci Med. 2005;61:2492-500.

26. Awases M, Gbary A, Nyoni J, Chatora R. Migration of health professionals in six countries: a synthesis report. World Health Organ. 2004;65:38-42.

27. Chikanda A. Skilled health professionals' migration and its impact on health delivery in Zimbabwe. J Ethn Migr Stud. 2006;32:667-80.

28. Association of American Medical Colleges. The Impact of Health Care Reform on the Future Supply and Demand for Physicians Updated Projections Through 2025. https://www.aamc.org/download/158076/data/ updated_projections_through_2025.pdf Available at: https://www.aamc.org/ download/158076/data/updated_projections_through_2025.pdf. (Accessed: 4 Aug 2015)

29. Association of American Medical Colleges. A Snapshot of the New and Developing Medical Schools in the US and Canada.pdf. Available at: https:// members.aamc.org/eweb/upload/A\%20Snapshot\%20of\%20the\%20 New\%20and\%20Developing\%20Medical\%20Schools\%20in\%20the\%20 US\%20and\%20Canada.pdf. (Accessed: 4 Aug 2015)

30. Kirch DG, Henderson MK, Dill MJ. Physician workforce projections in an era of health care reform. Annu Rev Med. 2012;63:435-45. 
31. Traverso G, McMahon GT. Residency training and international medical graduates: coming to America no more. JAMA. 2012;308:2193-4.

32. Whelan GP, Gary NE, Kostis J, Boulet JR, Hallock JA. The changing pool of international medical graduates seeking certification training in US graduate medical education programs. JAMA. 2002;288:1079-84.

33. Boulet JR, Norcini JJ, Whelan GP, Hallock JA, Seeling SS. The international medical graduate pipeline: recent trends in certification and residency training. Health Aff (Millwood). 2006;25:469-77.

34. Mullan F, Salsberg E, Weider K. Why a GME squeeze is unlikely. N Engl J Med. 2015;373:2397-9.

35. McAviney MB, Boulet JR, Kelly WC, Seeling SS, Opalek A. US citizens who graduated from medical schools outside the United Stated and Canada and received certification from the Educational Commission for Foreign Medical Graduates, 1983-2002. Acad Med. 2005;80:473-8.

36. Eckhert NL, van Zanten M. US-citizen international medical graduates-a boon for the workfoce? N Eng J Med. 2015;372:1686-7.

37. Tekian A, Boulet J. A longitudinal study of the characteristics and performances of medical students and graduates from the Arab countries. BMC Med Educ. 2015:15:200

38. Medical education in the Caribbean: quantifying the contribution of Caribbean-educated physicians to the primary care workforce in the United States. Acad Med. 2013;88(2):276-81.

39. Connell J, Zurn P, Stilwell B, Awases M, Braichet J-M. Sub-Saharan Africa: beyond the health worker migration crisis? Soc Sci Med. 2007;64:1876-91.

40. OECD. Foreign-born doctors and nurses in OECD countries by 25 main countries of origin, 2000/01 and 2010/11. 2015.

41. Williams PT, Whitcomb M, Kessler J. Quality of the family physician component of the AMA Masterfile. J Am Board Fam Pract. 1996;9:94-9.

42. Henderson M. Assessing the accuracy of three national physician sampling frames. J Gen Intern Med. 2015;30:1402.

43. Danish S. Key indicator in academic medicine: the physician workforce in the United States. Acad Med. 2012;87:236-7.

44. Torrey EF, Torrey BB, Bhutta ZA. The US distribution of physicians from lower income countries. PLoS One. 2012;7(3):e33076.

45. Boulet JR, Cooper RA, Seeling SS, Norcini JJ, McKinley DW. US citizens who obtain their medical degrees abroad: an overview, 1992-2006. Health Aff (Millwood). 2009;28:226-33.

46. Cometto G, Tulenko K, Muula AS, Krech R. Health workforce brain drain: from denouncing the challenge to solving the problem. PLoS Med. 2013;10: e1001514.

47. Shah RS. The international migration of health workers: ethics, rights, and justice. 2012.

48. Grignon $M$, Owusu $Y$, Sweetman $A$. The international migration of health professionals, Discussion Paper series, Forschungsinstitut zur Zukunft der Arbeit, No. 6517. 2012.

49. Aluttis C, Bishaw T, Frank MW. The workforce for health in a globalized contextglobal shortages and international migration. Glob. Health Action. 2014;7.

50. Kollar E, Buyx A. Ethics and policy of medical brain drain: a review. Swiss Med Wkly. 2013;143:W13845.

51. Sheikh M, Cometto G, Duvivier R. Universal health coverage and the post2015 agenda. Lancet. 2013;381:725-6.

\section{Submit your next manuscript to BioMed Central and we will help you at every step:}

- We accept pre-submission inquiries

- Our selector tool helps you to find the most relevant journal

- We provide round the clock customer support

- Convenient online submission

- Thorough peer review

- Inclusion in PubMed and all major indexing services

- Maximum visibility for your research

Submit your manuscript at www.biomedcentral.com/submit
Biomed Central 